\title{
Penjaminan Keberlanjutan Pembangunan Kapal Kayu Melalui Pelatihan Pembuatan Pola Gading untuk Penerapan Inovasi Gading Baja Sebagai Pengganti Gading Kayu bagi Pengrajin Kapal Kayu di Kabupaten Takalar
}

\author{
Lukman Bochary $^{1 *}$, Syamsul Asri ${ }^{1}$, Mohammad Rizal Firmansyah ${ }^{1}$, Muh. Rusydi Alwi ${ }^{2}$, \\ Rosmani $^{1}$, Misliah ${ }^{1}$, Ganding Sitepu ${ }^{1}$, Wihdat Djafar ${ }^{1}$ \\ Departemen Teknik Perkapalan, Fakultas Teknik, Universitas Hasanuddin ${ }^{*}$ \\ Departemen Teknik Sistem Perkapalan, Fakultas Teknik, Universitas Hasanuddin ${ }^{2}$ \\ didibochary@gmail.com ${ }^{1 *}$
}

\begin{abstract}
Abstrak
Sekarang ini bahan baku kayu untuk penggunaan gading atau rangka pada kapal kayu semakin sulit diperoleh karena mempunyai bentuk khusus, dimana kayu untuk gading kapal tersebut harus diambil dari pohon dalam bentuk balok yang sudah melengkung agar mudah dibentuk mengikuti bentuk kulit kapal kayu yang akan dibangun. Beberapa pengrajin kapal kayu di Sulawesi Selatan sudah menghadapi kesulitan ini. Salah satunya adalah pengrajin kapal kayu yang tergabung dalam kelompok pengrajin kapal kayu "TORANI" di Desa Galesong Kota, Kecamatan Galesong, Kabupaen Takalar. Kelompok pengrajin ini menghususkan memproduksi kapal perikanan dengan ukuran 10 GT sampai 30 GT. Untuk mengatasai masalah tersebut, perlu solusi bahan alternatif pengganti gading kayu. Sebuah penelitian telah menemukan alternatif bahan pengganti gading kayu yakni baja, dengan dimensi yang sesuai untuk digunakan pada kapal ikan 10 GT, 20 GT, dan 30 GT. Dimensi gading baja yang diperoleh ini memiliki sifat mendekati gading kayu tetapi dengan kekuatan yang lebih besar. Untuk dapat menerapkan gading baja pada kapal kayu tersebut, maka pengrajin mitra perlu dilatih dalam penggunaannya dimulai dari pengambilan pola, pembuatan dan pemasangan gading baja. Target mitra pada kegiatan pengabdian ini adalah pada tahap pertama proses penerapan gading baja pada kapal kayu yaitu mampu membuat pola gading baja. Pola ini nantinya dijadikan dasar dalam membuat gading baja pada kapal kayu yang mereka bangun. Metode pelaksanaan kegiatan adalah metode pelatihan dan pendampingan terhadap anggota mitra untuk membuat pola gading baja dengan dua tahapan sebagai berikut. Tahap pertama adalah penyuluhan dan pengenalan kepada mitra mengenai gading baja sebagai pengganti gading kayu dan tahap kedua adalah praktek dan pendampingan teknologi pembuatan pola gading baja. Tahap kedua ini meliputi pembimbingan peserta menggunakan peralatan dan perlengkapan pembuatan pola gading dan pembimbingan praktek membuat pola gading baja yang diambil dari bentuk kapal kayu dengan mengikuti lengkungan kulit kapal kayu.
\end{abstract}

Kata Kunci: Gading baja; kapal kayu; pengrajin kapal kayu; material alternatif; pelatihan.

\begin{abstract}
Currently wood raw material used for ivory or wooden ship frames is increasingly difficult to obtain because it has a special shape, where the wood for the ship's ivory must be taken from the tree in the form of curved beams, so that it is easily shaped according to the shape of the wooden ship that will be built. Some wooden ship craftsmen in South Sulawesi have faced this difficulty. One of them is a wooden ship craftsman who is part of a group of wooden ship craftsmen "TORANI" in Galesong Kota Village, Galesong District, Takalar. This group of craftsmen specifically produces fishing vessels with sizes of 10 GT to 30 GT. To overcome this problem, an alternative solution for wood ivory is needed. A study has found an alternative substitute for wood ivory, namely steel, with dimensions suitable for use on fishing vessels of $10 \mathrm{GT}, 20 \mathrm{GT}$, and $30 \mathrm{GT}$. The dimensions of the steel ivory obtained are close to the wood ivory but with greater strength. To be able to apply the steel ivory to the wooden ship, the partner craftsmen need to be trained in its use, starting from pattern taking, making and installing steel ivory. The target of partner activities in this service activity is in the first stage of the process of applying steel ivory to wooden ships, which is capable of making steel ivory patterns. This pattern will later be used as the basis for making steel ivory on the wooden ships they built. The method of the activity carried out was training and mentoring for partner members to make steel ivory patterns in two stages as follows: The first stage was counseling and introduction to partners
\end{abstract}


regarding steel ivory as a substitute for wood ivory; and the second stage is the practice and accompaniment of technology for making steel ivory patterns. The second stage includes guiding participants using equipment and equipment for making ivory patterns and guiding the practice of making steel ivory patterns taken from the shape of wooden ships by following the curves of the wooden ship's skin.

Keywords: Ivory steel; wooden ship; wooden ship craftsmen; alternative material; training.

\section{Pendahuluan}

Kapal kayu merupakan kapal yang masih banyak di gunakan di Indonesia baik sebagai kapal barang, kapal ikan, maupun kapal wisata. Dewasa ini kapal kayu semakin banyak di pesan baik dari dalam negeri maupun dari mancaneara khususnya kapal wisata yang dipergunakan untuk tujuan wisata bagi turis asing.

Hampir seluruh kapal kayu yang dibangun di Indonesia konstruksi kapalnya terbuat dari kayu, dimana pembuatan kapal kayu ini dilakukan oleh para pengrajin kapal kayu secara tradisional dengan keahlian yang didapatkan dari generasi ke generasi.

Sulawesi selatan adalah salah satu provinsi di Indonesia dimana banyak pengrajin kapal kayu yang membangun beragam kapal kayu dapat ditemui. Salah satu kelompok pengrajin kapal kayu yang ada di Sulawesi Selatan yaitu "Kelompok pengrajin kapal kayu TORANI" yang bertempat di Kelurahan Galesong Kota Kecamatan Galesong Utara Kabupaten Takalar. Kelompok pengrajin inilah yang menjadi mitra dalam pengabdian ini dimana fokus kegiatannya adalah memproduksi kapal perikanan dengan ukuran 10 GT sampai 30 GT.

Kendala yang dihadapi mitra saat ini adalah semakin sulitnya mendapatkan kayu untuk konstruksi gading karena bahan baku kayu untuk konstruksi ini terbilang khusus karena harus menggunakan balok kayu yang sudah melengkung dari pohonnya agar mudah dibentuk mengikuti lengkungan kulit kapal kayu (lihat gambar 1). Hal ini membuat harga kayu terutama untuk pembuatan gading menjadi sangat mahal. Hal ini juga ditambah dengan belum adanya bahan alternatif untuk menggantikan kayu dalam konstruksi gading kayu. Jika hal ini terus terjadi, maka dikhawatirkan kapal kayu tidak dapat lagi diproduksi oleh kelompok pengrajin kapal kayu di Sulawesi Selatan dan khususnya oleh kelompok pengrajin kapal kayu Torani di Kabupaten Takalar yang dijadikan mitra.

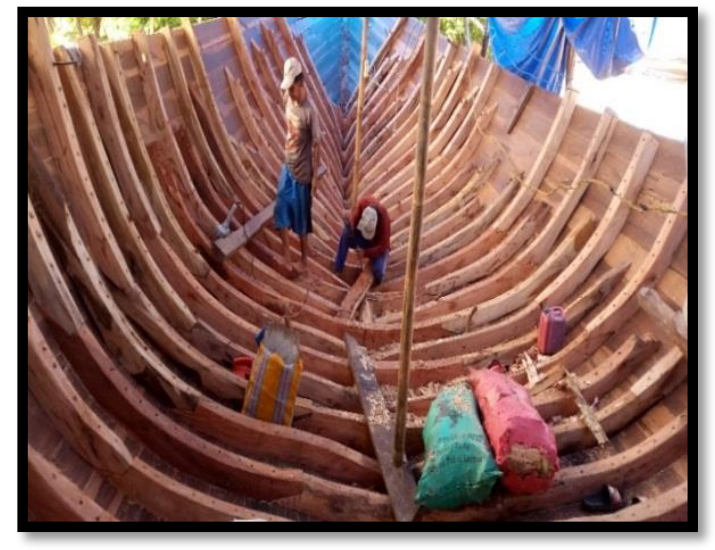


Gambar 1. Pengrajin kapal kayu sedang memasang konstruksi gading kayu yang melengkung pada kapal kayu

Untuk mendukung berlangsungnya pembangunan kapal kayu di Kabupaten Takalar dan Sulawesi Selatan pada umumnya, maka perlu dilakukan usaha untuk mencari material alternatif pengganti material kayu utamanya pada konstruksi gading kapal kayu karena semakin sulitnya memilih bentuk kayu yang cocok dengan bentuk lambung kapal kayu.

Dua studi telah dilakukan untuk mencari pengganti material kayu untuk konstruksi gading kayu. Dimana dalam penelitian tersebut material yang dipilih adalah baja. Hal ini dikarenakan penggunaan kayu pada konstruksi gading sangat besar sehingga penggantian material kayu pada konstruksi ini akan cukup signifikan menghemat penggunaan kayu. Baja dipilih karena mudah diperoleh, jumlahnya melimpah, kekuatan yang lebih besar dibanding kayu, serta mudah untuk dibentuk mengikuti bentuk kulit kapal kayu.

Penelitian pertama telah dilakukan oleh Bochary dan Larengi (2012) dengan judul penelitian "Alternatif Penggunaan Gading Baja pada Pembangunan Kapal Kayu (30 GT)". Penelitian ini membahas proses produksi dan bentuk gading baja yang cocok untuk kapal kayu. Penelitian kedua dilakukan oleh Bochary dkk (2018) dengan judul penelitian "Analisa Penggunaan Gading Baja Sebagai Pengganti Gading Kayu Dalam Upaya menunjang Pelestarian Hutan Serta Keberlanjutan Pembangunan Kapal Kayu ". Penelitian ini membahas dimensi gading baja yang sesuai untuk besarnya ukuran kapal kayu. Hasil dari penelitian ini adalah dimensi gading baja untuk kapal 10 GT, 20 GT, dan 30 GT. Dimensi gading yang diperoleh tersebut mendekati sifat gading kayu yang terpasang pada ketiga ukuran kapal tersebut diatas (lihat gambar 2).

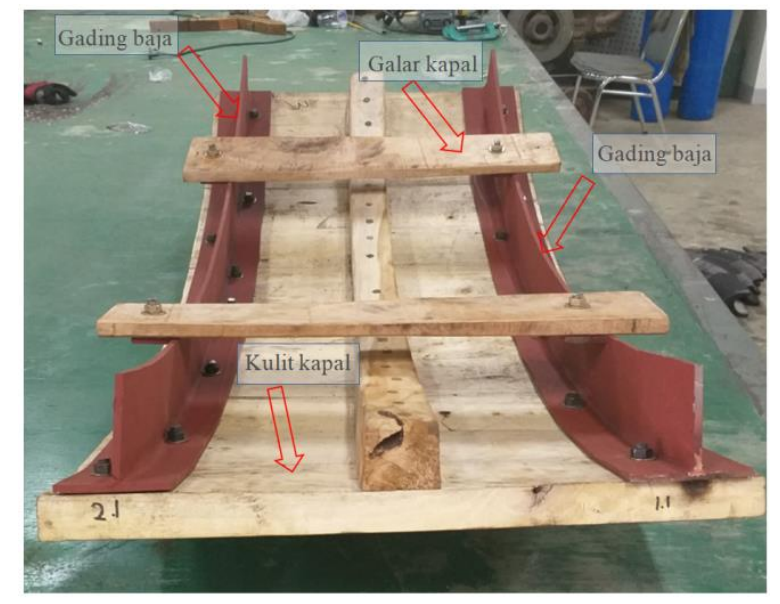

Gambar 2. Model gading baja pada konstruksi kapal kayu hasil penelitian yang dilakukan oleh Bochary dkk (2018)

Hasil penelitian gading baja sebagai pengganti gading kayu ini sudah disosialisasikan kepada beberapa pengrajin kapal kayu di Sulawesi Selatan namun sosialisasi yang dilakukan hanya terbatas pada pengenalan gading baja sebagai pengganti gading kayu pada konstruksi kapal kayu. Reaksi para pengrajin sangat antusias dan berharap agar penggunaan gading baja pada kapal kayu sebagai pengganti gading kayu dapat terealisasi segera. Mereka juga berharap bahwa ada 
semacam pelatihan yang diberikan kepada mereka berkaitan dengan tata cara pembuatan dan pemasangan gading baja pada konstruksi kapal kayu yang mereka bangun di masa depan.

Berdasarkan hasil sosialisasi di atas, maka perlu dilakukan kegiatan pengabdian untuk menindak lanjuti keinginan mereka untuk dapat menerapkan gading baja pada kapal kayu mereka. Penerapan gading baja pada kapal kayu terdiri dari beberapa tahapan. Pertama adalah pembuatan pola gading kemudian pembuatan gading dan yang ketiga adalah pemasangan gading baja. Pada kegiatan pengabdian ini akan dilakukan kegiatan tahap pertama yaitu pelatihan pembuatan pola gading baja. Selain itu, pada kegiatan ini juga akan diperkenalkan teknologi dan peralatan yang digunakan dalam pembuatan pola gading baja. Setelah itu, pada kegiatan selanjutnya, mereka diberikan pelatihan tahap dua dan tiga. Hal ini dilakukan secara bertahap disebabkan oleh keterbatasan waktu dan biaya yang tersedia.

\section{Konstruksi Kapal Kayu}

Gading adalah salah satu bagian konstruksi kapal yang paling penting karena gading inilah yang menjadi kerangka badan kapal dan sekaligus mendukung kekuatan memanjang kapal (Gambar 3.). Gading pada kapal dipasang pada sisi kapal pada posisi melintang dan sepanjang kapal dari lunas hingga tepi geladak utama. Pada gading ini jugalah kulit kapal melekat. Selain kulit, pada gading ini juga melekat galar kapal pada bagian dalam kapal dan sebagai penumpu balok geladak kapal (BKI 1992).

Tidak seperti pada kapal baja, gading pada kapal kayu umumnya adalah gading tunggal yaitu gading yang tidak menerus pada sisi kiri dan kanan kapal sehingga pada kapal kayu, gading pada sisi kiri dan kanan kapal terhubung pada lunas kapal.

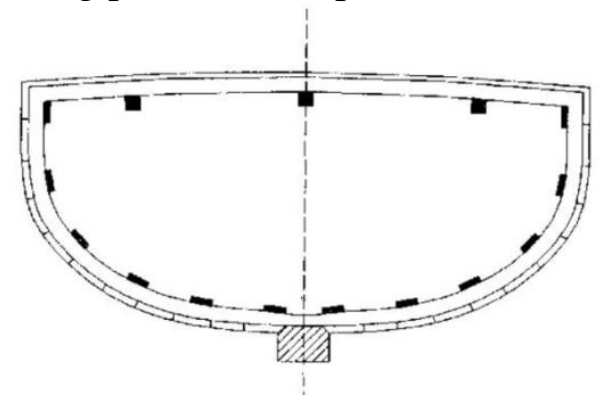

\section{Gambar 3. Konstruksi Gading Kapal Kayu}

Jarak antara gading pada kapal kayu diukur dari tengah gading yang satu ke gading yang lainnya dan jarak ini ditentukan berdasarkan daerah pelayaran kapal yang bersangkutan (Rauf dan Chaerunnisa, 2003).

Konstruksi gading pada kapal kayu agak sedikit berbeda dengan konstruksi gading pada kapal baja. Jika gading pada kapal baja terdapat gading alas dan gading balik maka pada kapal kayu, kedua jenis gading ini tidak digunakan.

Gading gading pada kapal kayu umumnya dibuat dari kayu yang telah melengkung secara alami. Hal ini dilakukan karena profil gading kayu yang menerus ini akan memperkuat kekuatan kapal secara keseluruhan. Walaupun dalam keadaan tertentu gading kayu dapat disambung, tetapi prioritas diberikan kepada gading kayu menerus. Karena persyaratan inilah yang terkadang membuat relatif sulitnya untuk mendapatkan jenis kayu lengkung yang sesuai dengan kebutuhan gading kapal. 
Berdasarkan pada peraturan konstruksi kapal kayu pada Biro Klasifikasi Indonesia (1996), persyaratan untuk gading gading pada kapal kayu adalah sebagai berikut:

- Tebal gading dalam kamar mesin dan sekitar tiang layar harus diperbesar $20 \%$ dari ukuran yang disyaratkan

- Untuk gading lengkung, dapat digunakan bahan dari kayu yang urat uratnya sejalan dengan bentuk gadingnya.

- Jika kayu untuk gading tidak cukup panjang sesuai yang dibutuhkan, maka gading gading dapat disambung.

Dengan segala persyaratan untuk gading kayu diatas, upaya mencari kayu yang sesuai untuk digunakan pada kapal kayu menjadi lebih sulit. Akibatnya, banyak pohon kayu yang dipotong hanya untuk mencari profil kayu yang sesuai dengan bentuk dan karakteristik dari gading kayu. Jika hal ini dibiarkan terus menerus, akan terjadi penebangan hutan kayu yang relative sulit untuk dikontrol sehingga mengancam ekosistem dan pelestarian hutan kayu.

Dilain sisi, kebutuhan akan gading kayu tetap banyak. Untuk mengatasi hal ini, maka perlu dipertimbangkan untuk mencari alternatif pengganti gading kayu dengan material lain. Penggantian material gading kayu dengan material gading baja adalah menjadi pilihan yang rasional dengan beberapa pertimbangan sebagai berikut:

- Material baja mudah didapatkan

- Material baja telah terbukti lebih kuat dari material kayu

- Material baja mudah untuk dibentuk sesuai dengan kebutuhan gading kapal

- Material baja lebih murah jika dibanding dengan material kayu untuk satu bentuk gading

Pilihan penggantian material kayu pada gading kayu dengan material baja untuk gading kapal harus segera dilakukan karena semakin terbatasnya material kayu untuk kebutuhan gading yang tersedia. Namun demikian, pilihan penggantian belum dapat dilakukan karena belum pernah dilakukan analisis untuk menentukan dimensi gading baja yang sesuai untuk menggantikan gading kayu pada jenis kapal kayu dengan dimensi tertentu. Untungnya, penelitian berkaitan dengan gading baja ini telah dilakukan oleh Bochary dan Larengi (2012) dan Bochary dkk (2018).

\section{Metode untuk Menangani Permasalahan}

Untuk dapat menyelesaikan permasalahan mitra seperti diuraikan pada bagian sebelumnya, maka secara keseluruhan, solusi yang ditawarkan dapat diuraikan sebagai berikut:

(1) Memperkenalkan bahan baja sebagai pengganti gading kayu dan memperlihatkan kepada mitra keunggulan gading baja dibanding gading kayu berdasarkan hasil penelitian yang telah dilakukan.

(2) Memperkenalkan teknologi pembuatan gading baja dan peralatan yang harus dimiliki untuk dapat membuat gading baja pengganti gading kayu pada kapal kayu.

(3) Memperkenalkan teknologi pembuatan gading baja, mulai dari pembuatan pola sampai pada pembuatang gading.

\section{Target Capaian}

Secara keseluruhan, target akhir dari tim pengabdian adalah kemampuan pengrajin kapal dalam menerapkan inovasi gading baja pada konstruksi kapal kayu yang mereka bangun. Namun dalam prosesnya, membutuhkan beberapa tahapan pengabdian sehingga keseluruhan keterampilan 
dalam menerapkan gading baja pada konstruksi kapal kayu mereka dapat diperoleh. Pada tahapan pengabdian ini, target capaian adalah kemampuan dari para pengrajin kapal kayu dalam membuat pola gading baja. Selain itu, sudah diperkenalkan pengetahuan yang berkenan dengan tahapan selanjutnya hingga pemasangan gading baja pada konstruksi kapal kayu mereka setelah pengetahuan dan keterampilan pembuatan pola gading baja mereka dapatkan.

\section{Implementasi Kegiatan}

Pelaksanaan kegiatan pengabdian ini melibatkan 12 pengrajin kapal kayu. Pada tahap pertama dari kegiatan ini, dilaksanakan pemaparan teori pembuatan pola gading baja dari konstruksi lambung kapal kayu yang sudah dibangun (Gambar 4).

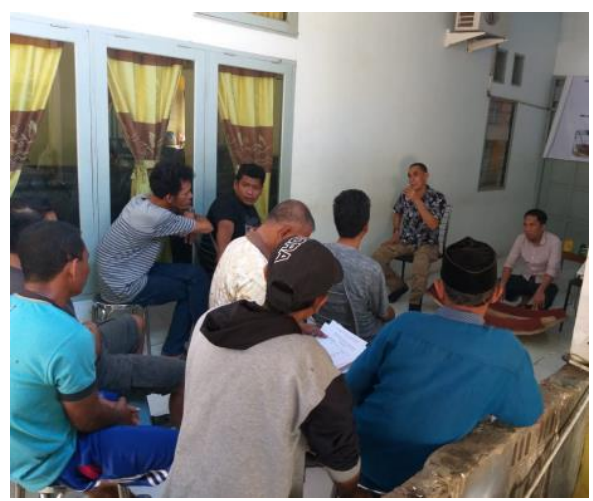

Gambar 4. Pemaparan teori pembuatan pola gading baja oleh tim pengabdian

a.

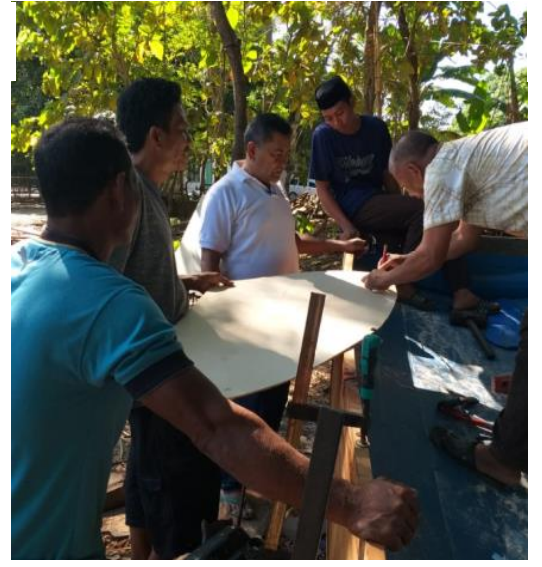

c.

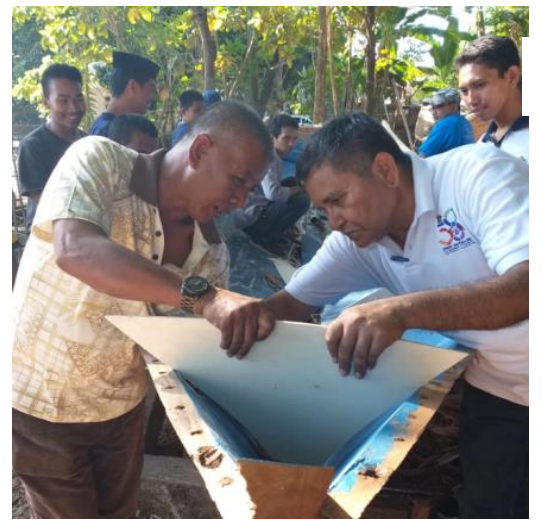

$\mathrm{b}$

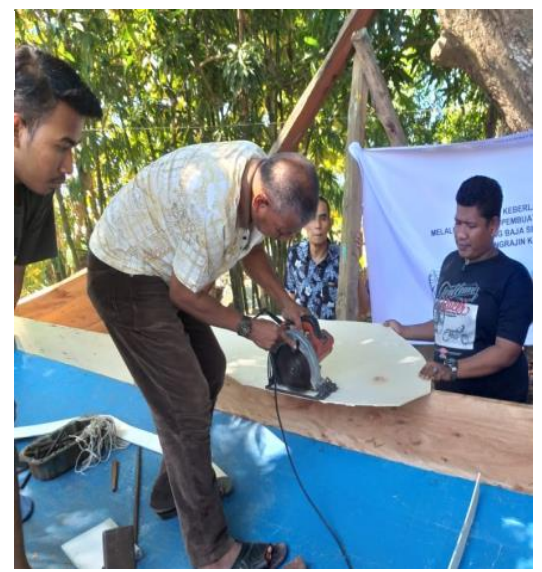

d.

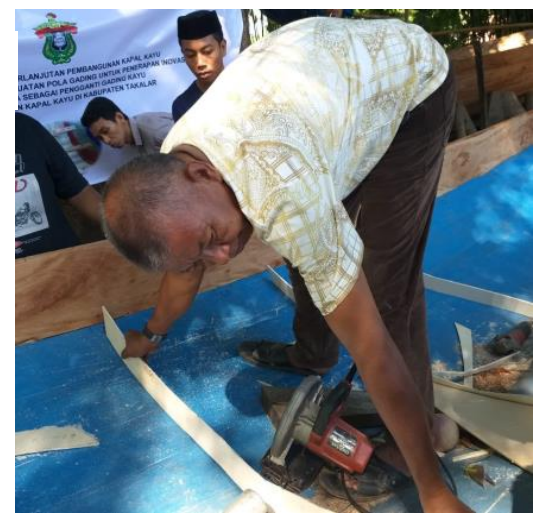


Gambar 5 (a-d). Latihan/praktik pembuatan pola gading baja

Pemaparan teori dilakukan oleh beberapa anggota tim pengabdian dari Departemen Teknik Perkapalan, Fakultas Teknik Unhas. Peralatan yang digunakan dalam pembuatan pola gading baja ini juga diperlihatkan kepada peserta pelatihan. Setelah itu dilanjutkan dengan sesi tanya jawab berkaitan dengan teori pembuatan gading baja ini. Kegiatan ini diakhiri dengan evaluasi awal pengetahuan tentang teori pembuatan pola gading baja ini terhadap peserta pelatihan. Hasilnya secara umum menunjukkan nilai yang baik.

Setelah tahapan pemaparan teori, dilanjutkan dengan latihan/praktik pembuatan pola gading baja secara langsung pada sebuah lambung kapal kayu yang sedang dibangun di galangan kapal ini. Latihan/praktik pembuatan pola gading baja ini dimulai dari mengukur dan mengambil pola atau bentuk gading pada kulit kapal sampai membuat bentuk gading dari triplex. Setiap pengrajin diberikan kesempatan untuk latihan/praktik membuat pola gading baja dibawah bimbingan tim pengabdian (Gambar 5a-d). Proses latihan/praktik pembuatan pola gading baja ini berlangsung selama beberapa hari. Proses latihan/praktik yang dilakukan oleh setiap peserta pelatihan langsung diikuti dengan proses evaluasi atas kemampuan masing masing pengrajin kapal kayu. Hasil akhir dari evaluasi yang dilakukan menunjukkan nilai yang baik karena dapat dikatakan bahwa $100 \%$ dari peserta pelatihan dapat dengan mudah membuat pola gading baja pada konstruksi kapal kayu.

\section{Hasil dan Diskusi}

Inovasi gading baja yang telah dihasilkan dari penelitian yang dilakukan oleh Bochary dkk (2018) perlu untuk diterapkan pada konstruksi kapal kayu yang dibangun di Sulawesi Selatan. Secara detail, proses penerapan ini harus melalui beberapa tahapan diantaranya adalah sosialisasi inovasi gading baja ini kepada para pengrajin kapal kayu di Sulawesi Selatan, pelatihan pembuatan pola gading baja, pelatihan proses marking pola ke pelat baja, pelatihan pemotongan pelat, pelatihan pengelasan dan terakhir adalah pelatihan pemasangan gading baja ke konstruksi kapal kayu.

Sosialisasi inovasi gading baja ini telah dilakukan dibeberapa daerah sentra pengrajin kapal kayu di Sulawesi Selatan. Setelah tahapan ini, pelatihan pembuatan pola gading baja juga harus dilakukan di daerah sentra pengrajin kapal kayu itu. Namun karena keterbatasan dana dan waktu, maka cakupan pelaksanaan harus dilaksanakan secara bertahap. Tahap pertama pelatihan pembuatan pola ini telah dilaksakanan di galangan kapal rakyat di kabupaten Takalar. Di galangan kapal kayu ini, sejumlah 12 pengrajin kapal kayu telah dilatih untuk membuat pola gading baja. Tingkat penyerapan materi pelatihan sangat baik karena metode pelatihan yang digunakan termasuk praktik dan latihan langsung pembuatan pola gading baja setelah pemaparan teori pembuatan gading baja dilakukan. Pada praktik pembuatan pola, setiap pengrajin diberikan kesempatan untuk membuat pola gading baja pada sebuah kapal kayu yang sedang dibangun di galangan kapal kayu ini. Hasilnya menunjukkan tingkat penyerapan maksimal karena masing masing pengrajin dapat pada akhirnya dengan mudah membuat pola gading baja ini. Diharapkan bahwa keterampilan yang telah dimiliki oleh 12 pengrajin kapal kayu ini akan dapat ditularkan kepada pengrajin kapal kayu lain di galangan kapal kayu itu sehingga nantinya semua pengrajin kapal kayu di galangan kapal kayu di Kabupaten Takalar dapat dengan mudah membuat pola gading baja. 
Dengan hasil ini, tim gading baja sangat optimis bahwa dalam waktu dekat setelah pengabdian dilakukan juga di galangan kapal kayu lain di Sulawesi Selatan, kapal kayu yang dibangun di provinsi ini akan mulai menggunakan gading baja sebagai pengganti gading kayu pada konstruksi kapal kayu mereka.

\section{Kesimpulan}

Tingkat pemahaman dan keterampilan para pengrajin kapal kayu yang mendapatkan pelatihan ini sangat baik. Hal ini terbukti dengan kemampuan masing masing pengrajin yang dapat membuat pola gading baja secara mandiri setelah mengikuti pelatihan ini. Target pelatihan berikutnya adalah membuat marking pola yang telah dibuat ke lembar pelat untuk dipotong sesuai dengan bentuk gading baja.

Beberapa pelatihan masih perlu diberikan kepada para pengrajin kayu ini termasuk diantaranya adalah pelatihan penggunaan mesin potong pelat yang bisa dilakukan dengan mesin brender atau dengan menggunakan gerinda, pelatihan pengelasan gading baja dan terakhir pelatihan pemasangan gading baja ke konstruksi kapal kayu.

Diharapkan dimasa depan, konstruksi kapal kayu yang dibangun di Sulawesi Selatan umumnya dan di galangan kapal kayu di Kabupaten Takalar akan menggunakan gading baja sebagai pengganti gading kayu sehingga keberlanjutan pembangunan kapal kayu di Sulawesi Selatan dapat terjamin.

\section{Ucapan Terima Kasih}

Terima kasih yang sebesar besarnya diberikan kepada Lembaga Penelitian dan Pengabdian Masyarakat, Universitas Hasanuddin atas hibah dana pengabdian kepada tim pengabdian dari Departemen Teknik Perkapalan Fakultas Teknik sehingga kegiatan pengabdian ini dapat terlaksana. Terima kasih juga diberikan kepada Kepala Desa Galesong Kota, Kecamatan Galesong, Kabupaten Takalar dan terutama kepada Daeng Ngampa dan para pengrajin kapal kayu di Galangan Kapal Kayu Galesong Kota yang telah baik secara langsung maupun tidak langsung memfasilitasi dan turut serta terlibat dalam pelaksanaan kegiatan ini.

\section{Daftar Pustaka}

Biro Klasifikasi Indonesia (BKI), (1992). Pedoman Pembangunan Perahu Layar Motor, Biro Klasifikasi Indonesia Unit Inkomar, Jakarta.

Bochary, L. dan Larengi, F, (2012). Alternatif penggunaan gading baja pada pembangunan kapal kayu 30 GT, Journal Riset Teknologi Kelautan, Volume 10, No. 2, Halaman 121-272, Makassar.

Bochary, L, Sitepu, G, Asri, S, Firmansyah, M. R (2018). Analisa Penggunaan Gading Baja sebagai pengganti gading kayu dalam upaya menunjang pelestarian hutan serta keberlanjutan pembangunan kapal kayu. Laporan Penelitian, Universitas Hasanuddin.

Rauf, A. M., dan Chaerunnisa, A, (2003). Pengembangan metode pembuatan kapal kayu tradisional di Kabupaten Bulukumba. Lembaga Penelitian Pengembangan Masyarakat Universitas Hasanuddin, Makassar

BKI. (1996). Peraturan Kapal Kayu. Biro Klasifikasi Indonesia. Jakarta. 